\title{
Automated minimax design of networks
}

\section{Madsen, Kaj; Schjær-Jacobsen, Hans; Voldby, J}

Published in:

IEEE Transactions on Circuits and Systems

Publication date:

1975

Document Version

Publisher's PDF, also known as Version of record

Link back to DTU Orbit

Citation (APA):

Madsen, K., Schjær-Jacobsen, H., \& Voldby, J. (1975). Automated minimax design of networks. IEEE Transactions on Circuits and Systems, 22(10), 791-796.

\section{General rights}

Copyright and moral rights for the publications made accessible in the public portal are retained by the authors and/or other copyright owners and it is a condition of accessing publications that users recognise and abide by the legal requirements associated with these rights.

- Users may download and print one copy of any publication from the public portal for the purpose of private study or research.

- You may not further distribute the material or use it for any profit-making activity or commercial gain

- You may freely distribute the URL identifying the publication in the public portal

If you believe that this document breaches copyright please contact us providing details, and we will remove access to the work immediately and investigate your claim 


\title{
Automated Minimax Design of Networks
}

\author{
KAJ MADSEN, HANS SCHJÆR-JACOBSEN, AND JØRGEN VOLDBY
}

\begin{abstract}
A new gradient algorithm for the solution of nonlinear minimax problems has been developed. The algorithm is well suited for automated minimax design of networks and it is very simple to use. It compares favorably with recent minimax and least $p$ th algorithms. General convergence problems related to minimax design of networks are discussed. Finally, minimax design of equalization networks for reflectiontype microwave amplifiers is carried out by means of the proposed algorithm.
\end{abstract}

\section{INTRODUCTION}

$\mathrm{I}$ N PRACTICAL circuit and systems design it is often required to approximate certain specified characteristics with physical realizable response functions in such a way that the maximum deviation is minimized. Such Chebyshev or minimax solutions are usually not obtainable by analytical means in general cases with arbitrary specifications or when strongly frequency dependent elements are used in broadband systems design. It is therefore well motivated to try to develop iterative schemes to achieve performance approximations that are optimum in the minimax sense.

Ishizaki and Watanabe [1] and Osborne and Watson [2] introduced very similar approaches with successive local linearizations of the nonlinear equations. However, these methods may fail to converge if certain singularities are present. Bandler et al. have developed an algorithm not requiring derivatives [3] and also an algorithm which uses gradient information of one of more of the highest ripples in the response error function [4]. Recent work by Bandler and Charalambous [5], [6] used at least pth approach together with a gradient optimization algorithm to provide minimax solutions.

This paper describes a new algorithm that is based on successive linear approximations to the nonlinear functions defining the problem. The resulting linear systems are solved in the minimax sense with automatically adjusted bounds on the solutions, depending on the goodness of the linear approximations. This approach has proved successful in least-squares approximation problems [7]. Unlike some of the previous developed methods, the present algorithm avoids expensive line searches. Although the method is intended for solution of a wide range of nonlinear minimax problems, it will be compared here with other algorithms solving cascaded transmission-line transformer problems. The versatility of the algorithm is finally demonstrated by optimal design of microwave reflection amplifiers.

Manuscript received July 12, 1974; revised November 19, 1974 and February 17, 1975.

K. Madsen is with the Institute for Numerical Analysis, Technical University of Denmark, DK-2800 Lyngby, Denmark.

H. Schjær-Jacobsen and J. Voldby are with the Electromagnetics Institute, Technical University of Denmark, DK-2800 Lyngby, Denmark.

\section{A New Algorithm}

\section{A. Mathematical Introduction}

The minimax problem under consideration is that of minimizing

$$
F(\underline{x})=\max _{j}\left|f_{j}(\underline{x})\right|
$$

where

$$
f_{j}(\underline{x})=f_{j}\left(x_{1}, x_{2}, \cdots, x_{n}\right), \quad j=1,2, \cdots, m, \quad m \geq n
$$

is a set of residuals which are nonlinear functions of the design parameters $\underline{x}$. In the frequency-domain design case $f_{j}$ may be thought of as the deviation of an actual network amplitude response $H\left(\underline{x}, \psi_{j}\right)$ from a desired response $H_{0}\left(\psi_{j}\right)$ at the $j$ th sample frequency $\psi_{j}$ :

$$
f_{j}\left(\underline{x}, \psi_{j}\right)=H\left(\underline{x}, \psi_{j}\right)-H_{0}\left(\psi_{j}\right) .
$$

At the $k$ th stage of the algorithm a minimax solution $\underline{h}_{k}$ to the linearized system

$$
f_{j}\left(\underline{x}_{k}\right)+\sum_{i=1}^{n} \frac{\partial f_{j}}{\partial x_{i}}\left(\underline{x}_{k}\right) h_{k i}=0, \quad j=1,2, \cdots, m
$$

is found subject to the constraints

$$
\left\|\underline{h}_{k}\right\|=\max _{i}\left|h_{k i}\right| \leq \lambda_{k} .
$$

$\lambda_{k}$ is automatically adjusted during the process to try to provide the inequality

$$
F\left(\underline{x}_{k}+\underline{h}_{k}\right)<F\left(\underline{x}_{k}\right)
$$

allowing a new approximate solution to be defined as

$$
\underline{x}_{k+1}=\underline{x}_{k}+\underline{h}_{k}
$$

Thus the value of $\lambda_{k}$ should depend on the goodness of the linear approximations to (2) at $\underline{x}=\underline{x}_{k}$. The more the residuals $f_{j}$ differ from a set of linear functions in the neighborhood of $\underline{x}_{k}$, the smaller $\lambda_{k}$ should be chosen. Correspondingly, if the linear approximations are very good, and $\underline{x}_{k}$ is not near a minimum, we will allow the next step to be larger by choosing a larger value of $\lambda_{k+1}$. This strategy offers a greal deal of flexibility because it allows the algorithm to adapt to the local behavior of $F(\underline{x})$.

\section{B. Detailed Mathematical Description}

Let $\bar{F}(\underline{x}, \underline{h})$ be defined through

$$
\bar{F}(\underline{x}, \underline{h})=\max _{j}\left|f_{j}(\underline{x})+\left(\underline{\nabla} f_{j}(\underline{x}), \underline{h}\right)\right|
$$

where

$$
\underline{\nabla} f_{j}(\underline{x})=\left(\frac{\partial f_{j}}{\partial x_{1}}(\underline{x}), \cdots, \frac{\partial f_{j}}{\partial x_{n}}(\underline{x})\right)
$$


Now $\underline{h}_{k}$ is found as solution to the linear problem

$$
\bar{F}\left(\underline{x}_{k}, \underline{h}_{k}\right)=\min _{\|\underline{h}\| \leq \lambda_{k}}\left\{\bar{F}\left(\underline{x}_{k}, \underline{h}\right)\right\} .
$$

This subproblem may be solved by a standard linear programming routine. However, we have solved the subproblem by a method similar to the exchange algorithm [9], which is more efficient than the linear programming method.

The point $\left(\underline{x}_{k}+\underline{h}_{k}\right)$ is chosen as the next point in the iteration, if the decrease in the function $F$ exceeds a small multiple of the decrease predicted by the linear approximation, i.e., if

$$
\Delta F_{k} \geq 0.01 \Delta \bar{F}_{k}
$$

where

$$
\Delta F_{k}=F\left(\underline{x}_{k}\right)-F\left(\underline{x}_{k}+\underline{h}_{k}\right)
$$

and

$$
\Delta \bar{F}_{k}=\bar{F}\left(\underline{x}_{k}, \underline{0}\right)-\bar{F}\left(\underline{x}_{k}, \underline{h}_{k}\right) .
$$

If (11) fails we let $\underline{x}_{k+1}=\underline{x}_{k}$.

The value $\lambda_{k+1}$ is defined as follows. If

$$
\Delta F_{k} \leq \alpha \Delta \bar{F}_{k}
$$

where $0.01<\alpha<1$, we choose $\lambda_{k+1}=\beta\left\|\underline{h}_{k}\right\|, 0<\beta<1$. As a consequence of this we will have $\lambda_{k+1} \leq \beta \lambda_{k}$ in the case where $\underline{x}_{k+1}=\underline{x}_{k}$. This strategy ensures convergence because (12) will be positive for $\left\|\underline{h}_{k}\right\|$ sufficiently small, unless a local minimum is reached. Experiments have shown that the values $\alpha=\beta=0.25$ are appropriate, so in the computer program we use these constants.

If (14) is not fulfilled, and

$$
\Delta^{2} \bar{F}_{k} \leq 0.25 \Delta F_{k}
$$

where

$\Delta^{2} \bar{F}_{k}=\max _{j}\left|f_{j}\left(\underline{x}_{k}+\underline{h}_{k}\right)-\left\{f_{j}\left(\underline{x}_{k}\right)+\left(\underline{\nabla} f_{j}\left(\underline{x}_{k}\right), \underline{h}_{k}\right)\right\}\right|$

is a measure of the goodness of the linear approximation, we choose $\lambda_{k+1}=2\left\|\underline{h}_{k}\right\|$. In practice this will mean that if the linear approximation is very good, and $\underline{x}_{k}$ is not near a local minimum, we will have $\lambda_{k+1}=2 \lambda_{k}$.

If neither (14) nor (15) is satisfied, we let $\lambda_{k+1}=\|\underline{h} k\|$.

For the sake of clarity, a flow-diagram of the algorithm is shown in Fig. 1.

The iterations are stopped whenever the convergence criterion

$$
\lambda_{k} \leq \varepsilon\left\|\underline{x}_{k}\right\|
$$

where $\varepsilon$ is a small user-spccified number, is met.

It can be shown that the algorithm has sure convergence properties. The interested reader is referred to [8] for the rather lengthy and space-consuming convergence proofs.

\section{Practical Implementation}

The proposed algorithm has been implemented for a digital computer (IBM 370/165) in double precision Fortran IV. The package is user-oriented and very simple to apply. The user only needs to know the parameter list of

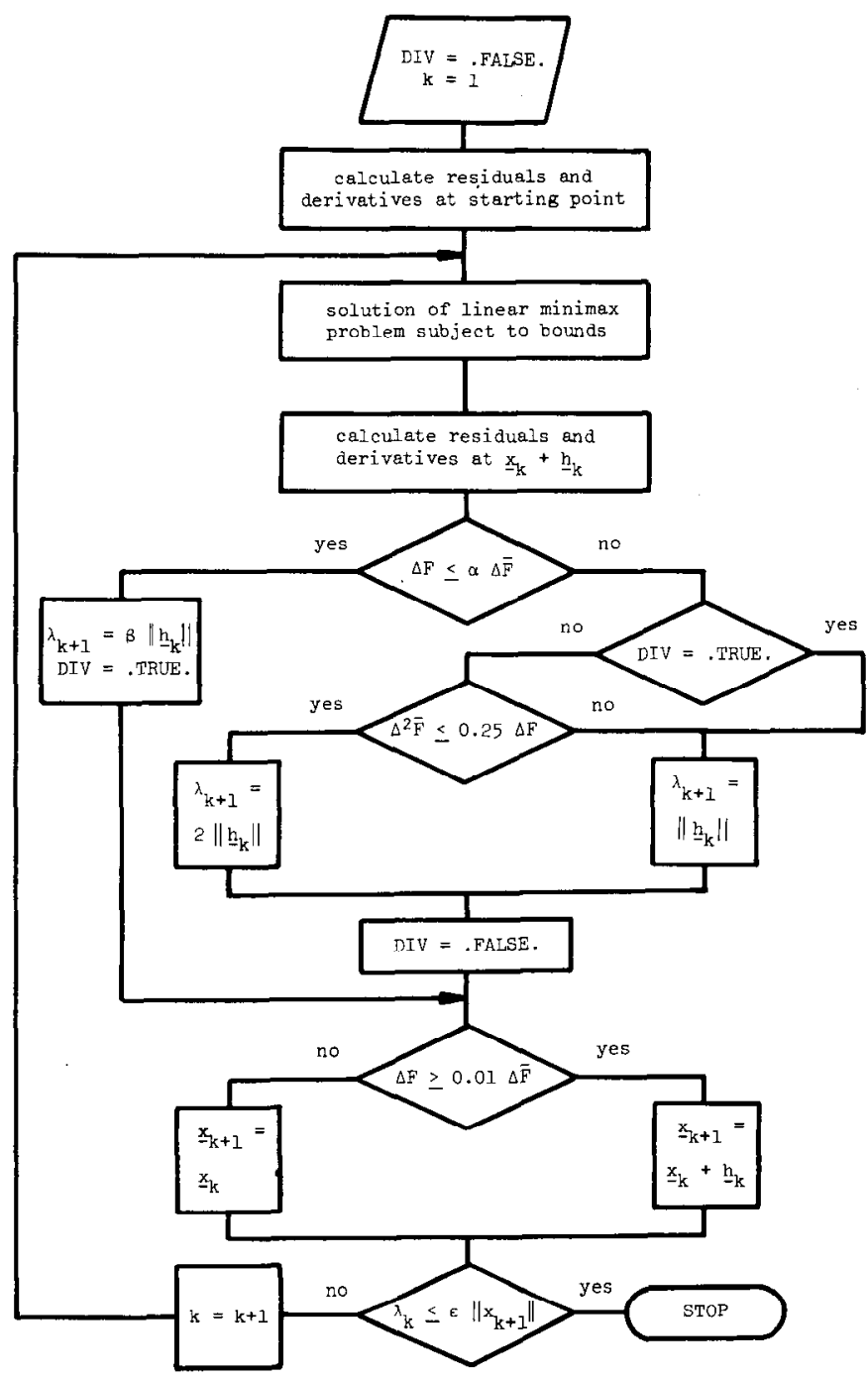

Fig. 1. Mathematical flow diagram of minimax algorithm.

the minimization subprogram and to code a subroutine for calculating the residuals and the sensitivities. On entry initial estimates of $\underline{x}$ and $\lambda$ should be provided together with parameters $n, m$, and $\varepsilon$. Since the bounds are adjusted by the subroutine the choice of the initial value of $\lambda$ is not critical. We suggest a value near 10 percent of the norm of the starting vector. In all the runs quoted in this paper the initial value of $\lambda$ has been set equal to 0.1 .

The program package is available from the authors on request.

\section{Numerical Results}

\section{A. Comparison with Other Alyorithms}

To compare the proposed algorithm with already published minimax and least $p$ th algorithms, the wellknown two- and three-section cascaded transmission-line 10:1 transformers, see Fig. 2, have been optimized over a 100-percent bandwidth. These test problems were introduced in [3]. The residuals $f_{j}$ have been correspondingly defined as

$$
f_{j}(\underline{x})=\frac{1}{2}\left|\rho_{j}(\underline{x})\right|^{2}, \quad j=1,2, \cdots, 11
$$


TABLE I

Optimization of Two-Section 10:1 Quarter-Wave Transformer Over 100-Percent Bandwitth

\begin{tabular}{|c|c|c|c|c|c|c|c|c|}
\hline \multicolumn{2}{|c|}{ Starting values } & \multicolumn{7}{|c|}{ Number of networks analysis } \\
\hline$z_{1}$ & $z_{2}$ & Razor $[3]$ & Grazor [4] & $\begin{array}{l}\text { Least } p^{\prime} \text { th [5] } \\
(p=100)\end{array}$ & $\begin{array}{l}\text { This } \\
1.0 \%\end{array}$ & $\begin{array}{l}\text { gorith } \\
0.1 \% \text {, }\end{array}$ & $0.01 \%$ & \\
\hline 1.0 & 3.0 & $\begin{array}{l}157 \\
207\end{array}$ & 126 & 22 & 9 & 11 & 13 & \\
\hline 1.0 & 6.0 & $\begin{array}{r}34 \\
152\end{array}$ & 83 & 30 & 9 & 9 & 12 & \\
\hline 3.5 & 6.0 & $\left.\begin{array}{l}223 \\
100\end{array}\right\}$ & 52 & 15 & 7 & 9 & 10 & . \\
\hline 3.5 & 3.0 & $\begin{array}{l}210 \\
163\end{array}$ & 29 & 14 & 8 & 11 & 13 & \\
\hline
\end{tabular}

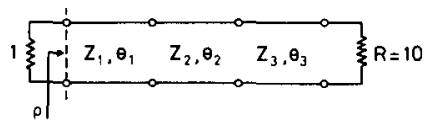

Fig. 2. Three-section cascaded transmission-line 10:1 transformer. Characteristic impedances $Z$ and electrical lengths $\theta$ (radians at center frequency).

where the 11 normalized sample frequencies $\psi_{j}$ are $\{0.5$, $0.6,0.7,0.77,0.9,1.0,1.1,1.23,1.3,1.4,1.5\}$ in the threesection case and uniformly spaced in the two-section case. The gradients $\partial f_{j} / \partial x_{i}$ are conveniently obtained using scattering matrix sensitivities [10], [11] based on the adjoint network concept [12], [13]. Since the network is reciprocal, only one network analysis is required to find the sensitivities. The basis of algorithm comparisons is the number of total network frequency analysis (including evaluation of the gradients) that is required to bring the maximum reflection coefficient

$$
\max _{j}\left|\rho_{j}\right|
$$

within 0.01 percent of its known optimum value for the two-section transformer (0.42857) and to bring (19) within 5 decimals accuracy $(0.19729)$ in the three-section case. For our method we also quote the number of iterations used to bring (19) within 1 percent, 0.1 percent, and 0.01 percent of the optimum value.

With fixed quarter-wave lengths some results are given for the two-section case in Fig. 3(a)-(d) as a function of the number of function evaluations $N$. Four different combinations of starting values of the characteristic impedances were used, namely, $\left(Z_{1}, Z_{2}\right)=(1.0,3.0),(1.0$, $6.0),(3.5,6.0)$, and $(3.5,3.0)$. The rate of convergence appears to be quite fast and in Table I comparisons are made with some previously published algorithms [3]-[5].

In Fig. 4 results for the three-section transformer are shown using the starting point $\left(Z_{1}, Z_{2}, Z_{3}\right)=(1.0,3.16228$, $10.0)$ and keeping the lengths fixed at the optimum values $\pi / 2$. In Table II, left column, also comparative results obtained in previous works [2]-[4] are tabulated.

The following two examples concerned with the threesection case varying both impedances and lengths exhibit

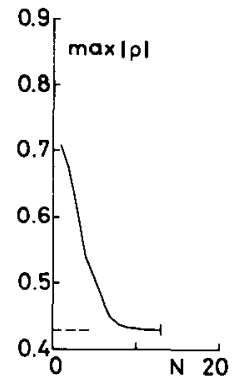

(a)

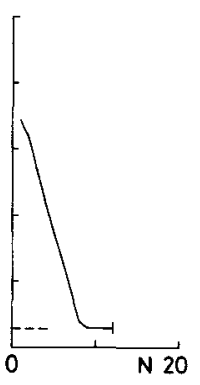

(b)

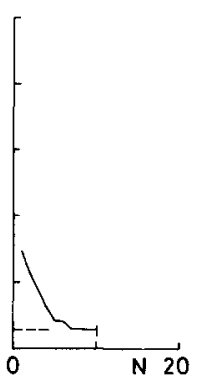

(c)

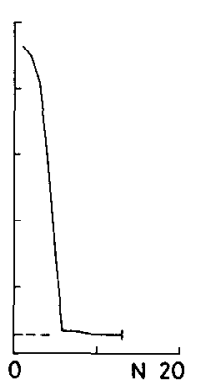

(d)
Fig. 3. Optimization of two-section 10:1 quarter-wave transformer over 100 -percent bandwidth to 0.01 percent accuracy. Starting points $\left(Z_{1}, Z_{2}\right)$ : (a) $(1.0,3.0)$, (b) $(1.0,6.0)$, (c) $(3.5,6.0)$, (d) $(3.5,3.0)$.

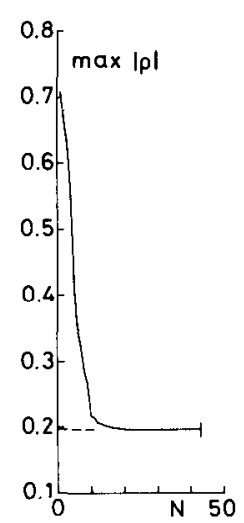

Fig. 4. Optimization of three-section 10:1 quarter-wave transformer over 100 -percent bandwidth to 0.01 percent accuracy. Starting point $\left(Z_{1}, Z_{2}, Z_{3}\right):(1.0,3.16228,10.0)$.

a type of singularity-at the solution that causes extremely slow final convergence. From the discussion in Section IV it follows that when the system is singular at the solution, $\alpha$ ought to be chosen smaller and $\beta$ larger than in the nonsingular case. In order to illustrate this point we present the number of function evaluations used by our algorithm for various values of $(\alpha, \beta)$ in Table II, right columns. The numbers also illustrate the point that the initial rate of convergence will normally not be affected by the singularity of the system. Also the corresponding results from the 
TABLE II

OPtIMIZation OF ThreE-Section 10:1 Transformer OVer 100-PERCENT BANDWIDTH

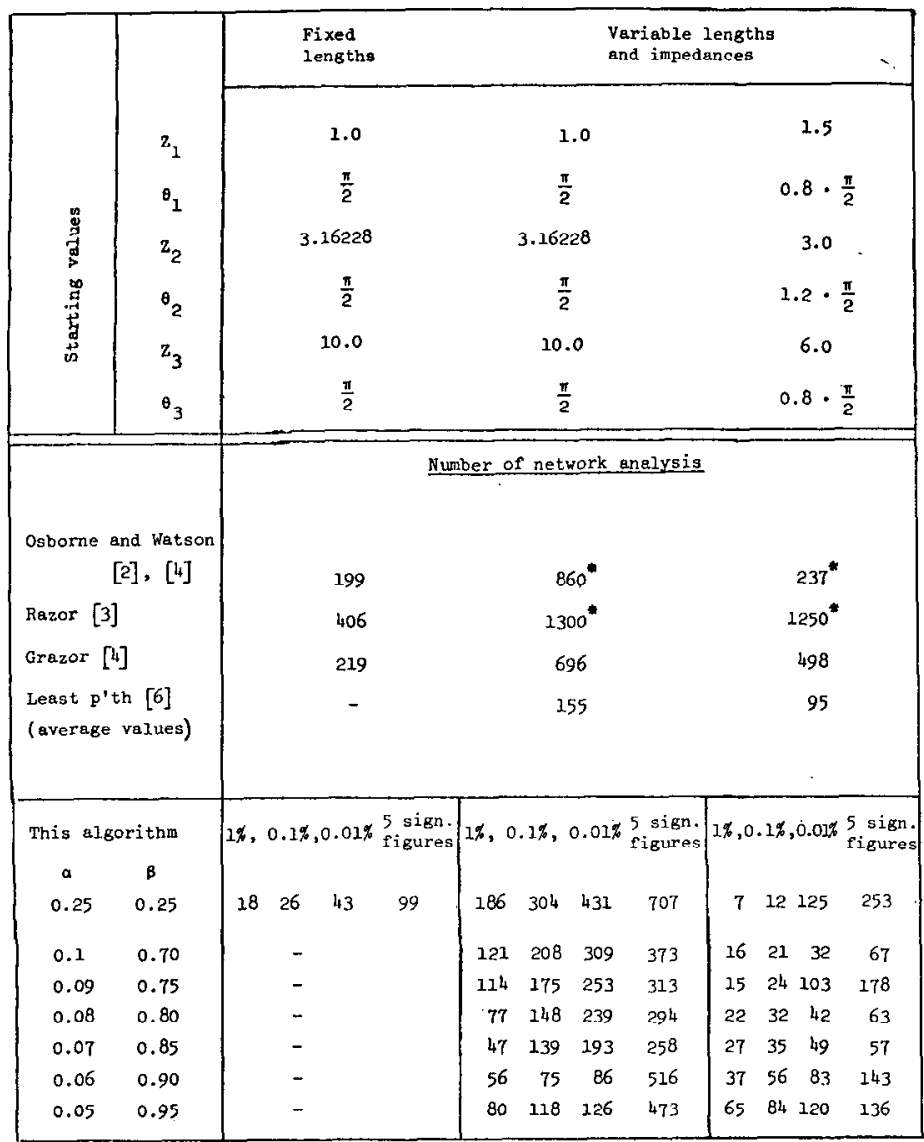

* Solution not reached with required accuracy.

literature [2]-[4], [6] are quoted. In [6] two least $p$ th algorithms (with modifications) were presented. However, for the sake of brevity only the most favorable results are quoted here.

From Tables I and II it occurs that our algorithm performs quite good on the particular test problems under consideration.

\section{B. Optimum Design of Reflection Amplifiers}

Consider a reflection amplifier with a transferred electron device represented by its measured small signal impedance, Fig. 5. An equalization network consisting of cascaded transmission line sections in front of the device is assumed in order to provide tuning facilities. The entire amplifier is then adequately modeled in analogy with the transformers previously described in Fig. 2, the voltage gain at the sample frequency $\psi_{j}$ being given by $\left|\rho_{j}\right|$. The residuals are defined by

$$
f_{j}(\underline{x})=\frac{1}{2}\left(\left|\rho_{j}(\underline{x})\right|-G_{0}\right)^{2}, \quad j=1, \cdots, 15
$$

where $G_{0}$ denotes the desired voltage gain within the frequency band $8.0-10.8 \mathrm{GHz}$ and the sample frequencies are equidistantly spaced.

Both impedances and lengths are allowed to vary and from identical starting points $\left(Z_{1}, Z_{2}, \theta_{1}, \theta_{2}\right)=(1.0,1.0$,

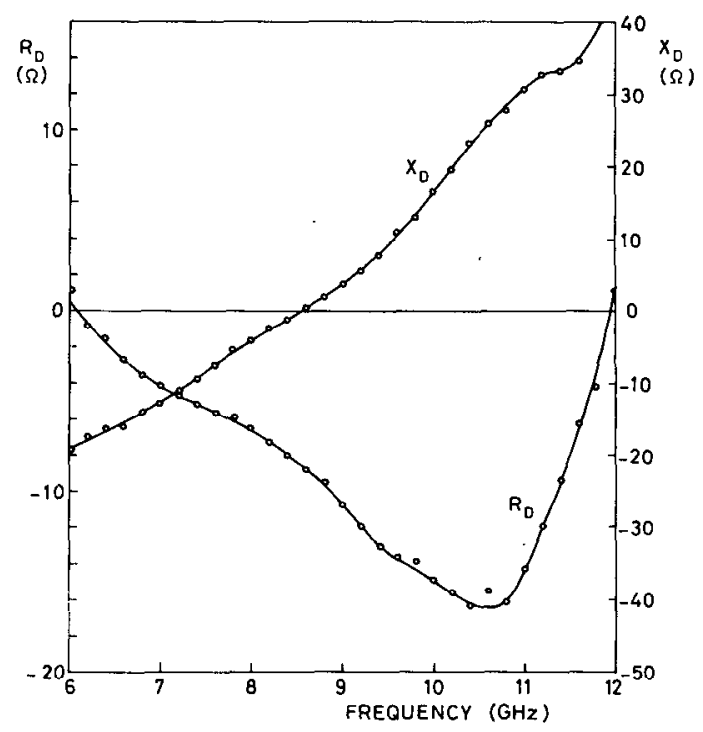

Fig. 5. Measured small signal impedance $Z_{D}=R_{D}+j X_{D}$ of packaged transferred electron device. Device data: $n_{0}=1.5 \cdot 10^{1 \mathrm{~s}}$ $\mathrm{cm}^{-3}, L=12 \mu \mathrm{m}, R_{0}=5.6 \Omega, V_{0}=-8.7 \mathrm{~V}$.

TABLE III

Optimization of Two-Section EQUalization NeTworks for Transferred Electron Amplifier in Frequency INTERVAL $8.0-10.8 \mathrm{GHz}\left(\varepsilon=10^{-5}, \alpha=\beta=0.25\right)$

\begin{tabular}{|c|c|c|c|c|c|}
\hline $\begin{array}{c}\text { SPECIFIED } \\
\text { VOLTAGE GAIN }\end{array}$ & $\mathrm{z}_{1}^{*}$ & $0_{1}$ & $\mathrm{z}_{2}^{*}$ & $\theta_{2}$ & $\begin{array}{l}\text { FUSICTIOM } \\
\text { EVALUATIONS }\end{array}$ \\
\hline 3.5 & 0.401868 & 2.13885 & 0.114232 & 0.302374 & 125 \\
3.0 & 0.441668 & 2.044808 & 0.209277 & 0.535822 & 118 \\
2.5 & 0.481489 & 1.94140 & 0.300273 & 0.738606 & 27 \\
2.0 & 0.521104 & 1.82380 & 0.409896 & 0.907693 & 66 \\
\hline \hline INITIAL & 1.0 & $\frac{\pi}{2}$ & 1.0 & $\frac{\pi}{2}$ & - \\
VALUES & & & & & \\
\hline
\end{tabular}

* Normalized to $50 \Omega$.

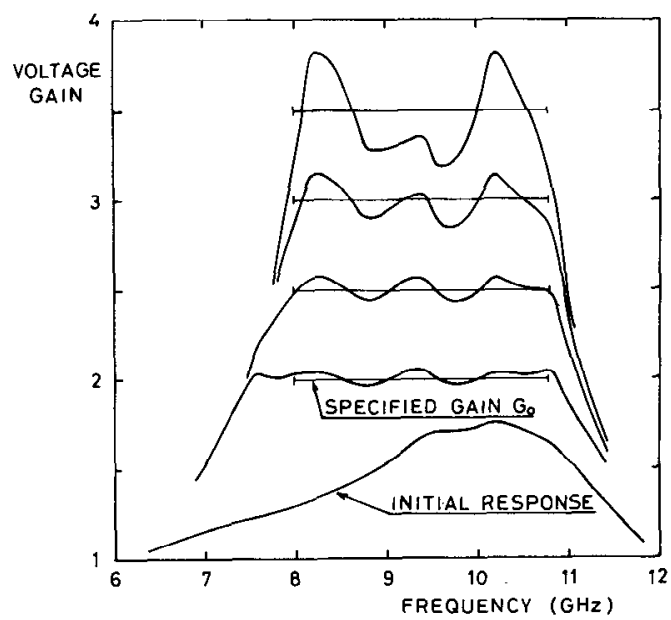

Fig. 6. Minimax transferred electron amplifier responses corresponding to different target gain specifications. 
$\pi / 2, \pi / 2)$ results are revealed in Table III and Fig. 6. Note that the starting point corresponds to the nonexistence of a tuning structure, i.e., no a priori information has been used in selecting the initial values of the optimization parameters.

It has not been the purpose of this section to deal with problems such as stability, discontinuity capacitances, device package parameters, etc., related to reflection-type amplifiers. Concerning these problems, the interested reader is referred to the literature, for example, [14].

\section{DISCUSSION}

The last two test problems considered in Scction III-A belong to a class of minimax problems that are singular in the following sense. Normally, at a minimax solution the extreme values of the residuals are attained in at least $n+1$ points. In these two test problems, however, $n=6$, but the optimum response only has $r=4$ maxima [3]. Because of the continuity this means that near the solution $r$ of the functions $f_{j}$ will determine $F(x)$, and it can be shown that the corresponding $r$ linear approximations of the form (4) are linearly dependent. Therefore, the unrestricted solution to (4) may not exist, and if it exists it will have the property $\left\|\underline{h}_{k}\right\| \rightarrow \infty$. Consequently, we obtain convergence only because of the bounds (5). This inconvenience may of course be eliminated, if, for example, the line lengths are kept fixed at the optimum values while searching for the optimum impedances.

Because of the linear dependence $F(\underline{x})$ describes a steep valley near the optimum, and, consequently, the linear approximations must be very accurate in order to ensure a decreasing sequence of function values. This means that (14) often will be satisfied and as a result the bound on the step lengths will be very small, which means many iterations. Therefore, the conditions for decreasing the bound must be mild, which means that $\alpha$ must be smaller and that $\beta$ must be larger.

Note that the difficulty only occurs when $\underline{x}_{k}$ is near the optimum, so we will have a fast initial convergence in all cases. The rather slow final convergence in the singular case is characteristic for methods using the objective function $F(\underline{x})$ (this method, [1]-[4]), whereas methods that work with smoother objective functions (e.g., [6]) probably are superior at this point. When our algorithm is applied to nonsingular problems, the final rate of convergence is quadratic [8]. If, however, it is known in advance that the problem is singular we adjust the constants $\alpha$ and $\beta$ to improve the final rate of convergence.

\section{Conclusion}

A nonlinear minimax optimization method has been developed and documented. The comparisons that have been carried out with published algorithms seem to indicate that the proposed algorithm is quite effective in achieving optimal minimax solutions to specific network design problems. Also more practical design problems have been satisfactorily solved by the algorithm, namely, design of equilization networks for microwave reflection-type amplifiers using measured small-signal data for the active device.
The problems arising from singularities have been briefly discussed and suggestions have been made as to increase the final rate of convergence in such singular cases.

It is believed that the present method will find widely spread applications within the field of network design and other fields in which solution of nonlinear minimax problems is essential.

\section{ACKNOWLEDGMENT}

The GaAs-transferred electron device used in Section III-B was fabricated at the Microwave Institute Foundation, Stockholm, Sweden, and furnished by B. Jeppsson. O. Nielsen is gratefully acknowledged for having supplied measured data of the device.

\section{REFERENCES}

[1] Y. Ishizaki and H. Watanabe, "An iterative Chebyshev approximation method for network design," IEEE Trans. Circuit Theory, vol. CT-15, pp. 326-336, Dec. 1968.

[2] M. R. Osborne and G. A. Watson, "An algorithm for minimax approximation in the nonlinear case," Comput. J., vol. 12, pp. 63-68, Feb. 1969.

[3] J. W. Bandler and P. A. Macdonald, "Optimization of microwave networks by razor search," IEEE Trans. Microwave Theory Tech., vol. MTT-17, pp. 552-562, Aug. 1969.

[4] J. W. Bandler, T. V. Srinivasan, and C. Charalambous, "Minimax optimization of networks by grazor search," IEEE Trans. Microwave Theory Tech, vol. MTT-20, pp. 596-604, Sept. 1972.

[5] J. W. Bandler and C. Charalambous, "Practical least $p$ th optimization of networks," IEEE Trans. Microwave Theory Tech., vol. MTT-20, pp. 834-840, Dec. 1972.

[6] C. Charalambous and J. W. Bandler, "New algorithms for network optimization," IEEE Trans. Microwave Theory Tech., vol. MTT-21, pp. 815-818, Dec. 1973.

[7] M. J., D. Powell, "Problems related to unconstrained optimization," in Numerical Methods for Unconstrained Optimization, W. Murray, Ed., Chapt. 3. London, England: Academic Press, 1972.

[8] K. Madsen, "An algorithm for minimax solution of overdetermined systems of non-linear equations," to be published in J. Inst. Math. Appl.

[9] M. J. D. Powell, "The minimax solution of linear equations subject to bounds on the variables," AERE Haswell, Oxfordshire, England, Rep. C.S.S. II, Dec. 1974.

[10] V. A. Monaco and P. Tiberio, "On linear network scattering matrix sensitivity," Alta Freq., vol. 39, pp. 193-195, Feb. 1970.

[11] J. W. Bandler and R. E. Seviora, "Wave sensitivities of networks," IEEE Trans. Microwave Theory Tech., vol. MTT-20, pp. 138-147, Feb. 1972

[12] S. W. Director and R. A. Rohrer, "The generalized adjoint network and network sensitivities," IEEE Trans. Circuit Theory, Vol. CT-16, pp. 318-323, Aug. 1969.

[13] S. W. Director and R. A. Rohrer, "Automated network designThe frequency-domain case," IEEE Trans. Circuit Theory, vol. CT-16, pp. 330-337, Aug. 1969.

[14] E. Hammershaimb, P. Jcppesen, and H. Schjær-Jacobsen, "Computer-aided design of broad band reflection type amplifiers," Int. J. Circuit Theory Appl., vol. 2, pp. 261-268, Sept. 1974.

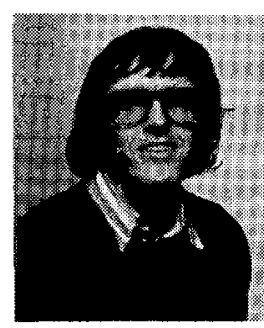

Kaj Madsen was born in Denmark in 1943. He received the cand. scient. degree in mathematics from the University of Aarhus, Aarhus, Denmark, in 1968.

He has been a Lecturer in numerical analysis at the Technical University of Denmark, Lyngby, since 1968, apart from the academic year 1973-1974, when he was at AERE Harwell, Didcot, England. His fields of interest in teaching and research are optimization and interval analysis. 


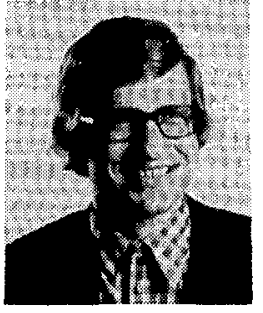

Hans Schjær-Jacobsen was born in Løgumkloster, Denmark, on December 30, 1943. After being educated as an electronics technician, he received the M.Sc. degree in electrical engineering from the Technical University of Denmark, Lyngby, Denmark, in 1972. At present he is with the Electromagnetics Institute, Technical University of Denmark, where he is working toward the Ph.D. degree.

He has carried out research in the fields of analysis and computer-aided design of antennas, microwave reflection amplifiers, and microwave filters. From 1972 to 1973, he worked on a research contract with ESTEC concerning multiple beam satellite antennas. His current research interest is in the development and application of numerical optimization methods for designing antennas and circuits.

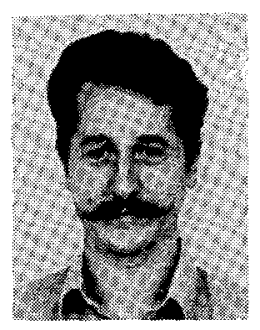

Jorgen Voldhy was born in Slagelse, Denmark, on October 24, 1946. He received the M.Sc. and $\mathrm{Ph} . \mathrm{D}$. degrees in electrical engineering from the Technical University of Denmark, Lyngby, Denmark in 1972 and 1975 , respectively.

From 1972 to 1975 , he worked on microwave circuit design and microwave radiometry at the Electromagnetics Institute, Technical University of Denmark. At present he is serving his compulsory military service.

\title{
Multiparameter Large-Change Sensitivity Analysis and Systematic Exploration
}

\author{
K. H. LEUNG, MEMBER, IEEE, AND ROBERT SPENCE, MEMBER, IEEE
}

\begin{abstract}
The effect on linear circuit response of simultaneous changes in a number $(m)$ of components must often be computed. Two efficient methods for predicting this effect are examined. It is shown that the computational cost of predicting the effect of each set is approximately $G_{m}$, where $G_{m}$ is the cost of a Gaussian elimination of an $m \times m$ matrix. However, if the sets represent combinations of relatively few individual component changes, then systematic exploration is shown to reduce the computational cost per set to the order of 2 .
\end{abstract}

\section{INTRODUCTION}

$\mathrm{T}$ HE NEED to compute the effect of component parameter change on circuit response arises from the frequent occasions during design and use when component values change either parasitically, manually or automatically (as in circuit optimization). In response to this need, sensitivity algorithms have been devised for calculating the effect of small changes in one or more parameters within a linear circuit [1]-[3]. For large changes, algorithms have

Manuscript received May 21, 1974; revised November 19, 1974 and March 8, 1975

The authors are with the Department of Electrical Engineering, Imperial College, Exhibition Road, London SW7 2BT, England. been proposed and investigated for changes in one [1], [4] or more [1], [5], [6] parameters, but there still exists a need for further assessment and comparative evaluation.

The effect of simultaneous large changes in more than one parameter is frequently of interest. The circuit designer may be interactively and dynamically adjusting a number of parameters in order to achieve a desired circuit response. Or, the changes may be automatic, as in a Monte-Carlo statistical circuit analysis [7]. The need to examine the consequence of change in the physical properties (e.g., temperature, doping level) of a circuit also involves the exploration of simultaneous parameter changes [8], as does the calculation of performance contours [9].

This paper examines two algorithms originally employed to predict the effect of single large parameter changes in a linear circuit, and determines their efficiency when extended to deal with simultaneous multiparameter variation. One outcome is an extremely efficient algorithm which is appropriate when the sets of component changes represent combinations of individual component changes. Engineering applications of this approach-known as systematic exploration-are briefly illustrated. 